\title{
Clinical Profile of Cerebral Schistosomiasis Patients in the Philippine General Hospital: A Retrospective Study
}

\author{
Ida Ingrid I. Rocha and Carissa Paz C. Dioquino
}

Department of Neurosciences, College of Medicine and Philippine General Hospital, University of the Philippines Manila

\begin{abstract}
Objective. To describe the clinical profile of cerebral schistosomiasis patients seen in the Philippine General Hospital from 2001 to 2011.

Method. This is a retrospective study of thirty-two cases with a diagnosis of "cerebral schistosomiasis". Records were reviewed for demographic data, comorbid conditions, presenting symptoms and signs, imaging findings, treatment and outcome. Information was summarized in a data collection sheet and descriptive analysis was done.

Results and Conclusion. Thirty-two patients treated for cerebral schistosomiasis were predominantly adult males from endemic provinces who presented with seizures and headache, with or without vomiting. Common neurologic findings were long tract signs, cranial nerve palsies and papilledema. Typical imaging findings were multiple nodules seen usually in the parietal lobe, with concomitant perilesional edema. Three-fourths of the patients showed clinical improvement with praziquantel on follow up.
\end{abstract}

Key Words: neuroschistosomiasis, central nervous system schistosomiasis, seizures

\section{Introduction}

Schistosomiasis is one of the leading parasitic infections afflicting man. Five species have been identified as causing clinical disease in humans. S. haematobium causes urinary schistosomiasis in African and Eastern Mediterranean countries. S. mansoni causes intestinal schistosomiasis also in these countries as well as in Caribbean and South American countries. S. intercalatum has been reported to cause another form of intestinal schistosomiasis in seven African countries. S. mekongi and S. japonicum cause the so-called Oriental or

Poster presented at the Philippine Neurological Association Annual Convention Research Forum, November 2011, Edsa Shangrila Hotel, Mandaluyong City.

Corresponding author: Ida Ingrid I. Rocha, MD

Department of Neurosciences

Philippine General Hospital

University of the Philippines Manila

Taft Avenue, Ermita, Manila 1000 Philippines

Telefax No.: +632 5548462

Email: idarocha.md@gmail.com
Asiatic intestinal schistosomiasis, endemic in Southeast Asia and the Western Pacific Region. ${ }^{1}$ Schistosoma japonicum is known to be endemic in China, Indonesia, and the Philippines. $^{2}$

Among the schistosomiasis species, S. japonicum is one of the most difficult to control due to its zoonotic nature. It uses animals such as carabaos, goats, pigs, rats, cats, and dogs as reservoir hosts. Despite efforts at mass treatment and environmental sanitation, schistosomiasis remains a serious public health burden in our country. The emergence of communal and national irrigation systems allowed the disease to spread even in the previously low or non-endemic areas. As of 2007, schistosomiasis remained endemic in 11 regions covering 28 provinces, 190 municipalities, 15 cities and 2,222 barangays. ${ }^{3}$

Acute schistosomiasis, or Katayama fever, is more commonly seen in previously unexposed persons and less commonly in heavy re-infections. Two to 12 weeks after exposure, patients present with fever, headache, myalgia, malaise, anorexia, non-productive cough, abdominal pain, diarrhea or bloody stools. On physical examination, there is generalized urticaria and a pruritic rash at the site of cercarial penetration, lymphadenopathy and eosinophilia in the blood 4-8 weeks after exposure. Patients may present initially with focal neurologic signs as a result of dissemination of eggs to the central nervous system. In some cases, eosinophil-mediated toxicity leading to vasculitis and small vessel thrombosis may be responsible for neurologic disease during acute infection. ${ }^{4}$

Schistosoma ova also provoke a chronic granulomatous inflammatory response in various tissues that may cause symptoms months or years after the initial infestation. Egg deposition can occur in any organ but those most commonly involved are the liver, intestines, lungs, and, less frequently, the central nervous system. ${ }^{5}$ Those with light infections present with fatigue, intermittent abdominal pain, and diarrhea. In heavy infections, anemia is common. ${ }^{6}$ Hepatosplenic disease is the most common serious manifestation of chronic schistosomiasis, characterized by ascites, hepatosplenomegaly and presence of collateral circulation from portal hypertension. In pulmonary involvement, cor pulmonale is the principal manifestation resulting from obstruction of pulmonary microvasculature due to granuloma formation and subsequent fibrosis. ${ }^{4}$ 
Involvement of the CNS occurs when ova reach the brain through arterial embolization, resulting in diffusely or randomly distributed lesions which are usually asymptomatic. It may also occur through retrograde venous migration of adult worms, resulting in localized, tumoral involvement. ${ }^{6,7}$ The deposition of eggs in the nervous system parenchyma incites an inflammatory reaction and mass effect, causing the nodular lesions and vasogenic edema seen on MRI. Both lead to variable neurologic manifestations, depending on the lesion site. Patients commonly present with headache, seizures, papilledema, visual abnormalities, speech disturbances, sensory impairment, hemiparesis, nystagmus, and ataxia. ${ }^{7}$ Linear enhancement seen on cranial imaging may be the result of worms causing local leptomeningneal vein obstruction, leading to ova accumulation, consequently forming a nodular mass. ${ }^{11}$ CNS schistosomiasis is most common with S. japonicum infection, occurring in as many as two to five percent of infections and accounting for high rates of epilepsy in endemic areas. On the other hand, S. mansoni and S. haematobium infections were more commonly implicated in myeloradiculopathy. ${ }^{1}$

In the Philippines, two to three percent of cases of general schistosomiasis were reported in 1986 to have symptomatic neuroschistosomiasis. ${ }^{8}$ An unpublished study in a tertiary medical center also reported 40 cases of neuroschistosomiasis seen from 1987 to 1991 . Of these, $60 \%$ complained of seizures and $22 \%$ had headaches. Other neurologic symptoms presented were dizziness, numbness, blurring of vision, loss of consciousness, imbalance, photophobia and memory impairment. On examination, the common findings were focal motor deficits, papilledema, and cerebellar signs. Several also presented with mental status changes and cranial nerve deficits. Half of the patients included in the study were treated with praziquantel, but their response was not assessed as most patients did not follow up. ${ }^{9}$

This study serves as an update on the limited data that so far exists concerning cerebral schistosomiasis in our local setting. It aims to describe the clinical profile of cerebral schistosomiasis patients seen in the Philippine General Hospital from 2001 to 2011.

\section{Objectives}

This paper will outline the clinical presentation of cerebral schistosomiasis patients in the Philippine General Hospital, as well as their imaging findings, treatment course and outcome.

\section{Materials and Methods}

This is a retrospective study. Censuses at the medical records section and outpatient department were searched for charts with a diagnosis of "cerebral schistosomiasis". Demographic data, comorbid conditions, presenting symptoms and signs, imaging findings, treatment, and outcome for each case were summarized in a data collection sheet and descriptive analysis was done using Microsoft Excel. Patients were classified according to diagnosis, whether histologically definite, probable, possible, or presumptive neuroschistosomiasis (Table 1). Outcome was defined as response to treatment; improvement denotes clinical resolution of symptoms such as seizures and headache. Patients who were symptomatic and had typical imaging findings but were negative in any of the previously mentioned laboratory tests were not included in the study population. All patient information was kept anonymous and confidential.

Table 1. Classification of diagnoses

\begin{tabular}{llc}
\hline \multicolumn{1}{c}{ Diagnosis } & \multicolumn{1}{c}{ Definition } & $\begin{array}{c}\text { No. of } \\
\text { Patients }\end{array}$ \\
\hline $\begin{array}{l}\text { Histologically } \\
\text { definite }\end{array}$ & $\begin{array}{l}\text { Demonstration of S. japonicum eggs by } \\
\text { brain biopsy or autopsy }\end{array}$ & None \\
Probable & $\begin{array}{l}\text { Presence of neurologic signs and } \\
\text { Neuroschistosomiasis }\end{array}$ & 26 \\
& $\begin{array}{l}\text { symptoms with positive laboratory } \\
\text { tests for schistosomiasis (COPT, Kato- }\end{array}$ & \\
& $\begin{array}{l}\text { Katz, or rectal imprint) and with } \\
\text { imaging findings characteristic of }\end{array}$ & \\
neuroschistosomiasis & \\
Possible & $\begin{array}{l}\text { Presence of neurologic signs and } \\
\text { Neuroschistosomiasis }\end{array}$ & $\begin{array}{l}\text { symptoms with positive laboratory } \\
\text { tests for schistosomiasis but no imaging }\end{array}$ \\
Presumptive & $\begin{array}{l}\text { Presence of neurologic signs and } \\
\text { Neuroschistosomiasis }\end{array}$ & 2 \\
& $\begin{array}{l}\text { symptoms in patients with history of } \\
\text { exposure to freshwater in an endemic }\end{array}$ & \\
& $\begin{array}{l}\text { area, with negative laboratory tests and } \\
\text { nolesions on imaging }\end{array}$ & \\
\hline
\end{tabular}

\section{Results}

In our search for medical records, 50 cases were found within the period of 2001 to 2011. Of these, 29 charts were available for review.

\section{Demographic Data}

The age range of the patients seen was 13 to 68 years old; the median age was 31 years old. About half of the patients were in the third to fourth decades of life. More males were affected than females, with a male to female ratio of $3: 1$. $62 \%$ of the patients originated from schistosomiasisendemic areas. The majority of patients were from the provinces of Samar and Leyte; one each came from Sorsogon, Surigao del Norte, and Agusan. The other patients came from Manila, Cavite, Laguna, Marikina, and Paranaque. In all, $75.9 \%$ of the patients had travel history to endemic areas.

Few comorbid conditions were documented: $13.8 \%$ had hypertension; one patient each $(3.4 \%)$ had a history of pulmonary tuberculosis, bronchial asthma, and renal disease; $10.3 \%$ of patients were previously assessed to have liver parenchymal disease probably secondary to schistosomiasis based on ultrasound findings. 


\section{Clinical Findings}

Patient characteristics are summarized in Table 2. The most common presenting symptom was seizures occurring in 22 patients $(75.9 \%)$. Of these, $12(54.5 \%)$ had generalized tonic clonic seizures, five $(22.7 \%)$ had complex partial seizures, and five $(22.7 \%)$ had simple partial seizures. Seventeen patients $(58.6 \%)$ presented with headache, eight $(27.6 \%)$ had nausea and vomiting, nine $(31 \%)$ had either numbness or weakness, seven $(24 \%)$ had dizziness and four $(13.8 \%)$ complained of blurring of vision. Twelve patients $(41.4 \%)$ were seen at the outpatient department. Sixteen patients $(55.2 \%)$ were admitted - seven of them due to acute symptomatic seizures, and seven due to symptoms of increased intracranial pressure (ICP). One patient had both an acute seizure and increased ICP, and one presented with a stroke-like syndrome.

Table 2. Patient characteristics

\begin{tabular}{|c|c|}
\hline \multicolumn{2}{|l|}{ Gender } \\
\hline Male & 22 \\
\hline Female & 7 \\
\hline \multicolumn{2}{|l|}{ Travel History } \\
\hline Samar & 6 \\
\hline Leyte & 7 \\
\hline Sorsogon & 1 \\
\hline Surigao del Norte & 1 \\
\hline Agusan & 1 \\
\hline \multicolumn{2}{|l|}{ Comorbid Conditions } \\
\hline Hypertension & 4 \\
\hline Pulmonary TB & 1 \\
\hline Bronchial Asthma & 1 \\
\hline Renal Disease & 1 \\
\hline \multicolumn{2}{|l|}{ Presenting Symptoms } \\
\hline Seizures & 22 \\
\hline Headache & 15 \\
\hline Nausea/vomiting & 8 \\
\hline Numbness/weakness & 9 \\
\hline Dizziness & 7 \\
\hline Blurred Vision & 4 \\
\hline \multicolumn{2}{|l|}{ Neurologic exam Findings } \\
\hline Higher cortical dysfunction & 6 \\
\hline Cranial Nerve Palsies & 9 \\
\hline Papilledema & 7 \\
\hline Motor deficits & 5 \\
\hline Sensory deficits & 6 \\
\hline Long tract signs & 9 \\
\hline Cerebellar signs & 0 \\
\hline
\end{tabular}

The leading neurologic exam findings were long tract signs (hyperreflexia, extensor toe sign) in nine patients (31\%), cranial nerve palsies (fifth, sixth, and seventh nerve) in eight patients $(27.6 \%)$, and papilledema in seven patients (24\%). Deficits in higher cortical functions such as apraxia and word-finding difficulty were noted in six patients $(20.7 \%)$. Six patients also had sensory deficits, whereas five $(17.2 \%)$ had focal motor deficits. Two patients $(6.9 \%)$ had visual field cuts and one (3.4\%) had cerebellar ataxia.

\section{Laboratory Findings}

Among the patients in this study, 26 had a laboratoryproven diagnosis, and one had a clinically presumptive diagnosis (Table 1). Two were clinical suspects-one came from an endemic area and the other had ultrasound findings of hepatic schistosomiasis. Rectal imprint was positive in 16 patients $(55 \%)$. Circumoval precipitin test (COPT) was positive in 14 (48\%) patients; Kato-Katz was positive in nine (31\%). Two patients had a previous history of a positive COPT test for which they were treated with praziquantel prior to diagnosis of cerebral schistosomiasis. There was no histologically confirmed case in this group of patients. Figure 1 shows the distribution of positive test results in our study population. Table 3 summarizes the laboratory and imaging findings of our patients.

Table 3. Laboratory and imaging findings

\begin{tabular}{lc}
\hline Laboratory Findings & \\
Rectal Imprint & 16 positive \\
& 13 positive \\
COPT & 1 negative \\
& 9 positive \\
Kato Katz & 1 negative \\
& \\
Imaging Findings & \\
CT scan & 16 \\
Hyperdense & 3 \\
Hypodense & \\
MRI & 10 \\
Hyperintense & 2 \\
Hypointense & 9 \\
Solitary lesion & 18 \\
Multiple lesions & 11 \\
With cerebral edema and midline shift & 6 \\
With cerebral edema, no midline shift & \\
Lesion location & 20 \\
Parietal lobe & 12 \\
Frontal lobe & 7 \\
Temporal lobe & 7 \\
Occipital lobe & \\
Cerebellum & \\
\hline
\end{tabular}

Imaging Findings

Cranial CT scan was done in 18 patients $(62 \%)$, whereas $13(44.8 \%)$ had an MRI. Both tests were done in seven of these patients. Eighteen patients $(62 \%)$ had multiple nodules, whereas nine (31\%) had a solitary lesion. Contrast enhancement was noted among eight patients. The lesions on CT scan were hyperdense in 16 patients, and hypodense in three. Among those with MRI, lesions were hyperintense in 10 patients and hypointense in two. Six patients (21\%) had perilesional edema but no midline shift. Eleven patients $(38 \%)$ had perilesional edema as well as midline shift. Only nine patients were documented to have marked perilesional edema relative to nodule size, one had moderate perilesional edema, and two patients had mild perilesional edema. Hydrocephalus was not seen in 12 patients (41\%), and its presence or abscence was not mentioned in the remaining 17 (58.6\%). 


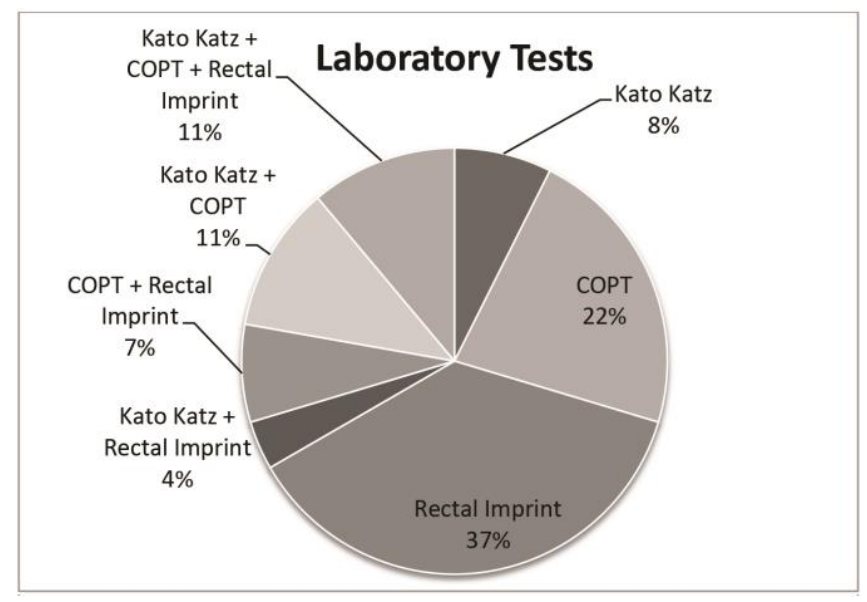

Figure 1. Distribution of positive test results among cerebral schistosomiasis patients

The parietal lobe was the most common lesion location, found in 21 patients (72\%), followed by the frontal lobe in 11 $(37.9 \%)$, followed equally by the temporal and occipital lobes in seven each $(24 \%)$. One patient had a lesion in the cerebellum.

The following are examples of imaging studies that demonstrate cerebral lesions in schistosomiasis patients. Figure 2 shows a cut from a plain cranial CT of an 18-yearold male from Sorsogon. He consulted for headache and generalized seizures. Schistosomiasis was confirmed by COPT and rectal imprint. On the scan, isodense to hyperdense enhancing foci with extensive surrounding white matter edema in the right frontal and high parietal regions were seen. A midline shift of $1.05 \mathrm{~cm}$ with compression of the right lateral ventricle was also noted. These are compatible with the typical imaging findings of cerebral schistosomiasis.

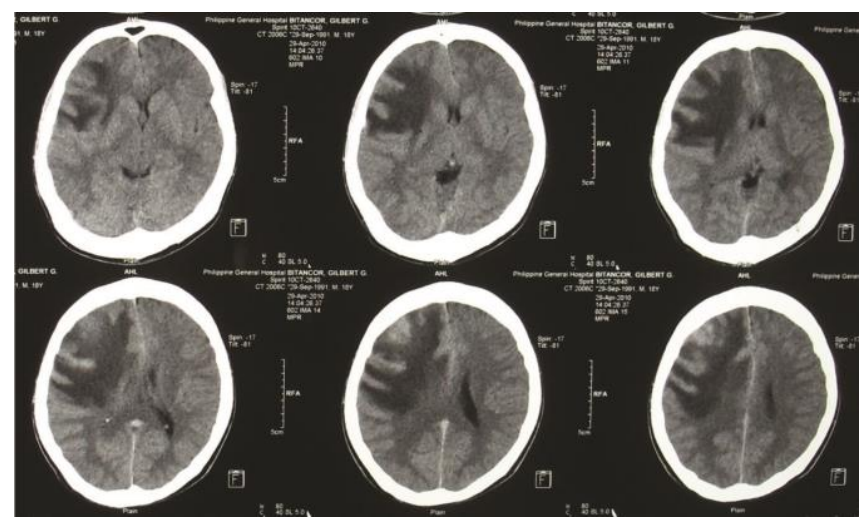

Figure 2. Cranial CT scan of an 18-year old male from Sorsogon who presented with headache and seizures, showing nodular enhancing lesions with vasogenic edema in the right frontal and anterior parietal lobes.
The following case demonstrates similar findings as seen on MRI. A 35-year-old male from Samar presented with generalized seizures. He tested positive for schistosoma on rectal imprint, and cranial MRI demonstrated multiple enhancing nodular masses on the left parietal area with surrounding edema (Figures 3 and 4). He was treated with praziquantel and anti-epileptic drugs, after which the seizures resolved.
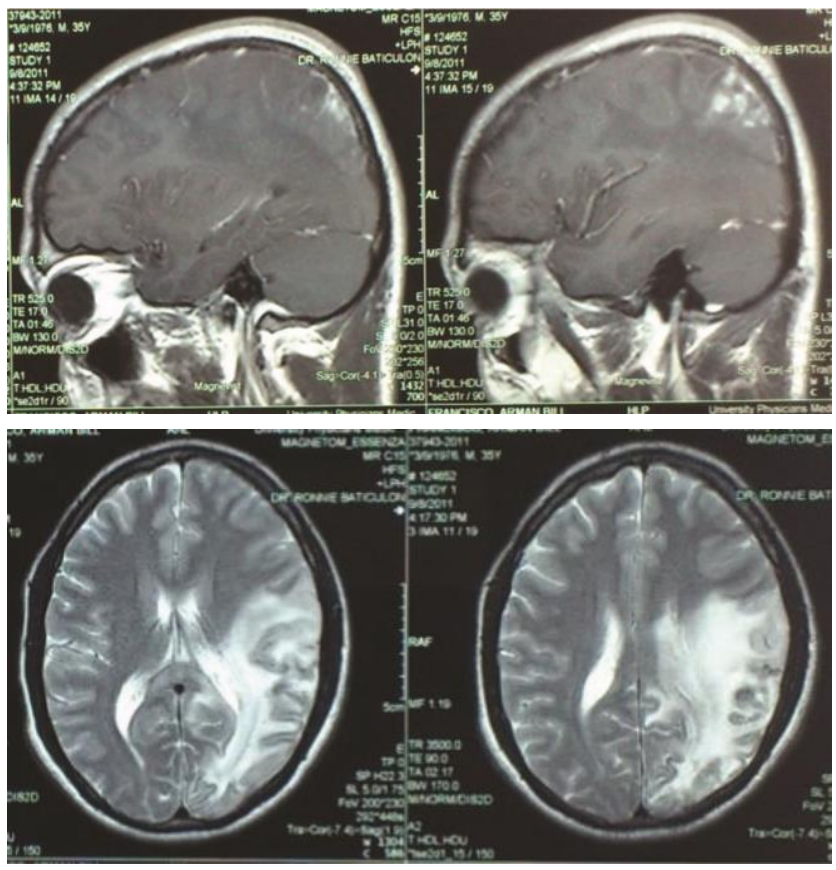

Figures 3 (top), 4 (bottom). Sagittal and axial MRI cuts of a 35/M from Samar who presented with generalized seizures, with nodular enhancing lesions and vasogenic edema as described.

The figures from our next case illustrate noticeable changes before and after treatment. A 51-year-old female from Northern Samar presented with focal seizures and left hemiparesis. Her rectal imprint was positive for schistosoma ova. Cranial CT scan (Figure 5) initially showed confluent, hyperdense enhancing nodules on the right parietal lobe with massive surrounding vasogenic edema and midline shift. Repeat CT scan a year after praziquantel treatment still showed multiple calcific densities on the right parietal lobe but with less perilesional edema. There was also note of some occipital parenchymal calcifications (Figure 6). Cranial MRI of the same patient a month after repeat CT scan showed enhancing foci on the right frontoparietal and occipital lobes as well as on the cortical and parasagittal areas of the left parietal lobe (Figures 7 A and B). 

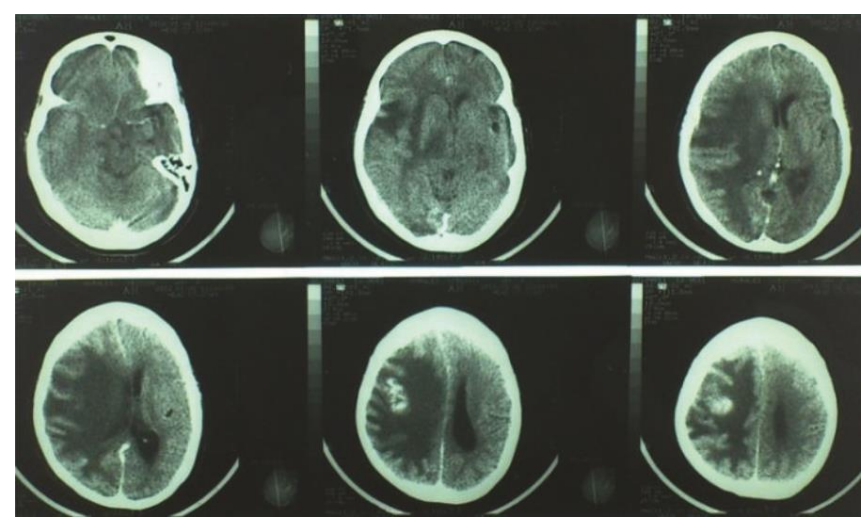

Figure 5. Cranial CT of a 51 y.o. female from Leyte

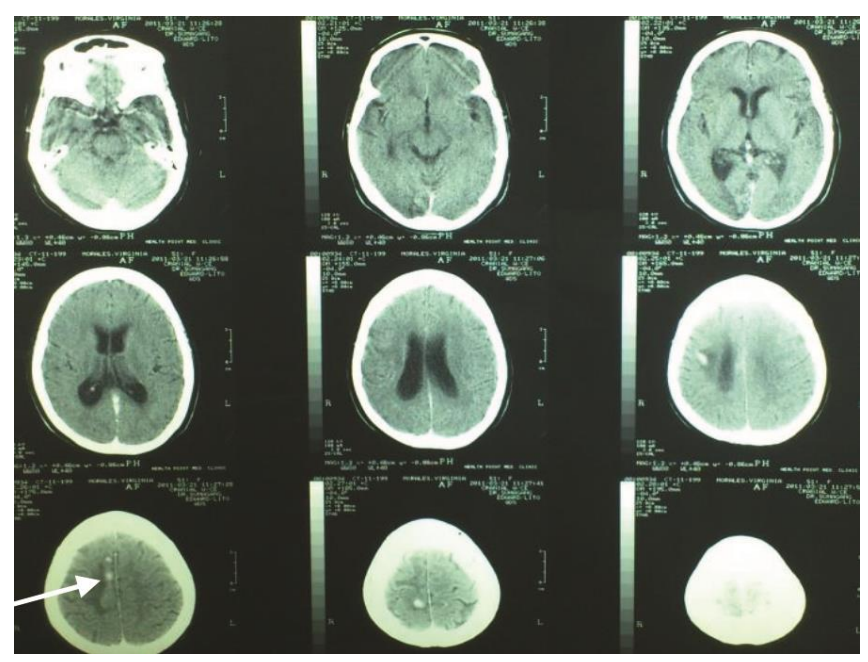

Figure 6. Cranial $\mathrm{CT}$ of the same patient 1 year after treatment.

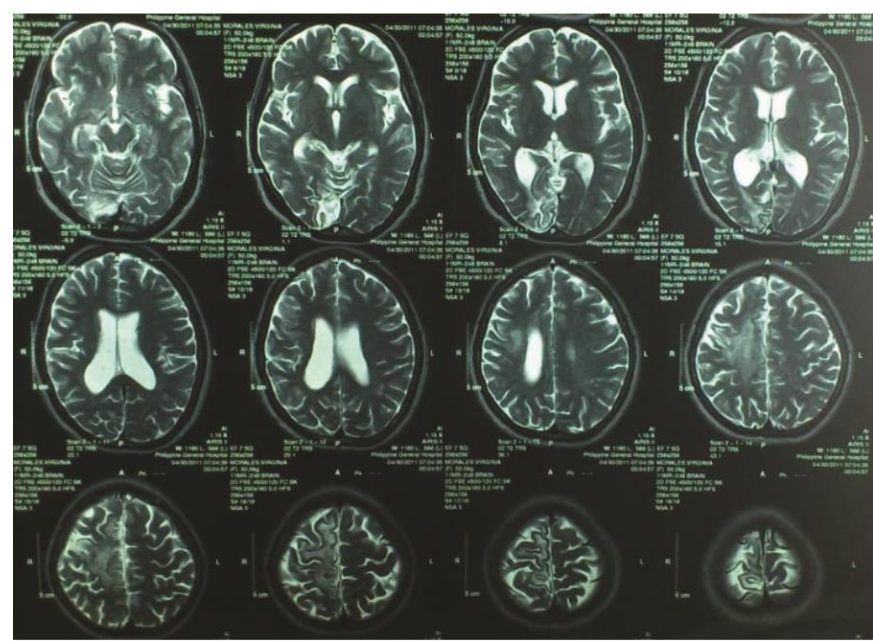

A

\section{Treatment and Outcome}

Twenty-eight patients underwent treatment with praziquantel, and 24 of them improved symptomatically. None underwent surgical intervention. The response to treatment in four patients was unknown. No mortalities were reported among those with known outcomes. All except two patients were given symptomatic treatment to address cerebral edema, seizures, and headache using steroids, anticonvulsants (such as phenytoin, carbamazepine, or phenobarbital), and analgesics as indicated.

\section{Discussion}

Though national surveys on the prevalence of schistosomiasis have been conducted periodically, few local published studies have specifically described the clinical profile of its neurologic involvement in Filipino patients. A review article by Ferrari and Moreira categorized the manifestations of neuroschistosomiasis into three forms: acute schistosomal encephalopathy (ASE), pseudotumoral encephalic schistosomiasis (PES), and spinal cord schistosomiasis (SCS). In the latter, the manifestations are acute or subacute onset of lower back pain, lower extremity weakness and sensory disturbances, abnormal deep tendon reflexes, bladder dysfunction, constipation and impotence, with marked improvement after treatment. In ASE, neurologic symptoms such as headache, altered mental status, seizures, and sensorimotor complaints occur 3 weeks after the onset of systemic disease. It usually develops in individuals without prior exposure or immunity. In PES, patients present with varying focal deficits caused by slowly expanding tumor-like lesions in different sites of the brain. It occurs most frequently among individuals from endemic areas without any other systemic symptoms of

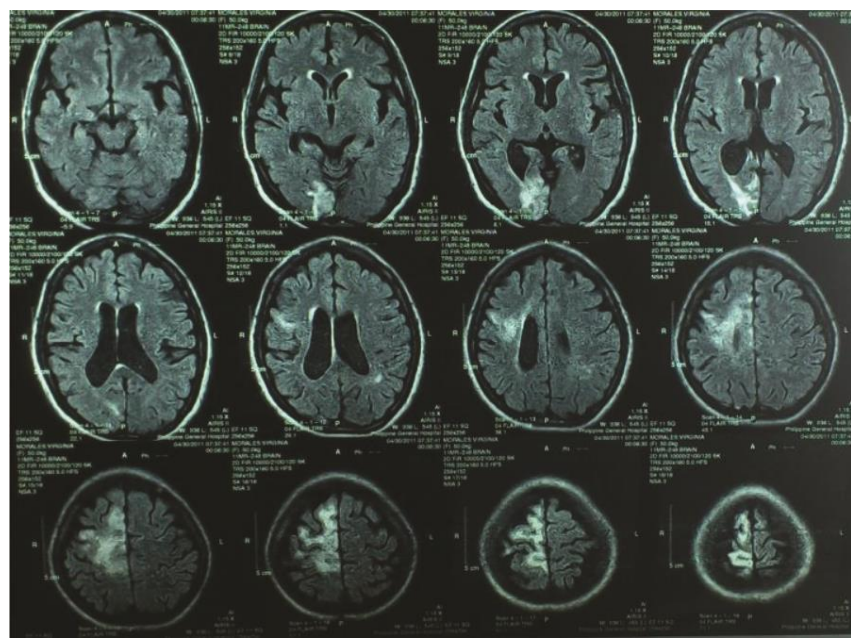

B

Figure 7. (A and B) MRI findings of the same patient on T2-weighted and T2 FLAIR sequences, respectively (done one year after treatment) 
schistosomiasis. ${ }^{10}$ The majority of patients in our review fall under the pseudotumoral category. Only three of our patients were found to have liver parenchymal disease, while the rest did not report other systemic symptoms of schistosomiasis. No case of spinal cord schistosomiasis has yet been documented.

In our study, 29 records were reviewed out of 50 cases of cerebral schistosomiasis identified within a period of 10 years. Our setting being a tertiary referral center, the majority of patients who consult already have a chronic form of schistosomiasis, hence the apparent low prevalence of acute cases and hepatic involvement.

Ferrari and Moreira also identified headache as the most common manifestation in 21 patients with the pseudotumoral form of schistosomiasis. Other common signs and symptoms were motor deficits, visual abnormalities, seizures, altered mental status, and vertigo. ${ }^{10}$ In contrast, our study showed seizures to be more frequent than headache. Similarly, other common manifestations among our subjects were sensorimotor deficits, dizziness, nausea and vomiting, and blurring of vision.

The imaging findings of nodular enhancing cerebral lesions with extensive vasogenic edema in our patients are similar to those previously reported in literature. The MRI findings of 33 patients with cerebral schistosomiasis in Anhui province and Shanghai, China showed multiple enhancing nodules with prominent perilesional edema and mass effect. ${ }^{11} \mathrm{CT}$ and MRI of 24 cases reviewed locally revealed solitary or multiple, small, isodense, sometimes calcified cortical nodules scattered in the brain parenchyma without following a vascular distribution. ${ }^{12}$ Massive edema suggests an acute process, whereas calcification and malacic changes are seen more with chronic lesions. Both studies have suggested considering cerebral schistosomiasis in patients with such lesions on neuro-imaging who have been exposed to an endemic area, developed neurologic symptoms, and tested positive on serology or stool sample tests. Among our study subjects, however, it is notable that two symptomatic patients were treated despite negative laboratory tests on the basis of liver findings of schistosomiasis and exposure of these patients to fresh water in endemic areas. Local government units have kept a high index of suspicion for schistosomiasis infection and have been taking this approach of treating patients with symptoms regardless of confirmatory laboratory test results. Yet millions of individuals remain exposed each year since mass chemotherapy has only reduced the prevalence but not completely eliminated schistosomiasis. ${ }^{13}$ In spite of this we see that the common clinical presentations in the Philippine setting differ from those described in other endemic countries, as mentioned earlier.

\section{Conclusion}

Patients treated for cerebral schistosomiasis at the Philippine General Hospital were mostly adult males from endemic provinces who presented with seizures and headache, with or without vomiting. Common neurologic findings were long tract signs, cranial nerve palsies, and papilledema. Typical imaging findings were multiple nodules seen usually in the parietal lobe, with concomitant perilesional edema. Three-fourths of the patients showed clinical improvement with praziquantel on follow up. Combining steroids and anticonvulsants with praziquantel yield a better clinical response.

\section{Recommendations}

Despite periodic mass distribution of praziquantel to exposed persons in endemic areas, schistosomiasis remains prevalent in the country. Having been conducted in a tertiary referral hospital, this study represents only a small percentage of the entire population affected in the provinces, and the clinical spectrum of neuroschistosomiasis described may vary if more patients are included.

It would also be worthwhile to devote a separate local study to describing MRI findings of patients with cerebral schistosomiasis before and after treatment. Only a few MRI cases were documented previously in a study done in two medical centers in the 1990s.

While praziquantel and steroids have been associated with good clinical improvement in this study as well as in previous reports, there remains a need for controlled trials to provide stronger evidence for the efficacy of praziquantel in cerebral schistosomiasis.

\section{References}

1. Clinical Practice Guidelines for the Diagnosis, Treatment and Prevention of Schistosoma japonicum infections in the Philippines: 2010 Update.

2. Chitsulo L, Engels D, Montresor A, Savioli L. The global status of schistosomiasis and its control. Acta Tropica. 2000; 77:41-51.

3. Department of Health. Schistosomiasis in the Philippines: Conference/Workshops on Schistosomiasis, Manila, December 2007.

4. Jaureguiberry S, Ansart S, Perez L, et al. Acute neuroschistosomiasis: two cases associated with cerebral vasculitis. Am J Trop Med Hyg. 2007; 76:964-6.

5. Garcia EG. Schistosomiasis Japonica. Philippine Council for Health Research \& Development, 1998.

6. Gryseels B, Polman K, Clerinx J, Kestens L. Human schistosomiasis. Lancet. 2006; 368:1106-18

7. Liu LX. Spinal and cerebral schistosomiasis. Semin Neurol. 1993; 13:189-200

8. Pittella JE, Gusmao SN, Carvalho GT, da Silveira RL, Campos GF. Tumoral form of cerebral schistosomiasis mansoni: A report of four cases and review of the literature. Clin Neurol Neurosurg. 1996:98:15-20.

9. Dioquino C. Cerebral schistosomiasis: the Philippine General Hospital experience from 1987-1991. Philippine General Hospital. Unpublished.

10. Ferrari TC, Moreira PR. Neuroschistosomiasis: clinical syndromes and pathogenesis. Lancet Neurol. 2011; 10(9):853-64.

11. Liu H, Lim CC, Feng X, et al. MRI in cerebral schistosomiasis: characteristic nodular enhancement in 33 patients. Am J Roentgenol. 2008; 191(2):582-8.

12. Adapon B, Dioquino C, Apolinar N. Neuroradiology of Cerebral Schistosomiasis. Unpublished.

13. Leonardo L, Rivera P, Saniel O, et al. A national baseline prevalence survey of Schistosomiasis in the Philippines using stratified two-step systematic cluster sampling design. J Trop Med. 2012; 2012:936128. 
Appendix. Patient characteristics, laboratory results, treatment, outcome

\begin{tabular}{|c|c|c|c|c|c|c|c|c|c|c|c|c|}
\hline $\mathbf{P t} \#$ & AGE & SEX & ORIGIN & AREA & $\begin{array}{l}\text { TRAVEL } \\
\text { HX }\end{array}$ & \begin{tabular}{|c|} 
WITH \\
NEURO \\
SIGNS/ \\
SYMPTOMS
\end{tabular} & IMAGING & $\begin{array}{l}\text { KATO } \\
\text { KATZ }\end{array}$ & COPT & $\begin{array}{l}\text { RECTAL } \\
\text { IMPRINT }\end{array}$ & $\begin{array}{c}\text { PZQ } \\
\text { TREATMENT }\end{array}$ & OUTCOME \\
\hline 1 & 13 & $\mathrm{~F}$ & Cebu & Manila & $?$ & $\mathrm{Y}$ & $\begin{array}{c}\text { Multiple nodules in } \\
\text { frontal, parietal, } \\
\text { temporal lobes; } \\
\text { marked edema }\end{array}$ & + & + & + & $Y$ & Improved \\
\hline 2 & 15 & M & Leyte & Mandaluyong & $\mathrm{Y}$ & Y & $\begin{array}{c}\text { Solitary enhancing } \\
\text { parietal nodule; } \\
\text { marked edema }\end{array}$ & + & + & + & $Y$ & Improved \\
\hline 3 & 16 & M & Laguna & Binan City & $?$ & Y & $\begin{array}{c}\text { multiple nodules in } \\
\text { frontal lobe; with } \\
\text { edema }\end{array}$ & + & $\begin{array}{l}\text { no } \\
\text { result }\end{array}$ & + & Y & Improved \\
\hline 4 & 18 & $\mathrm{M}$ & Manila & Caloocan & $\mathrm{Y}$ & $\mathrm{Y}$ & $\begin{array}{c}\text { multiple nodules in } \\
\text { frontal, temporal, } \\
\text { occipital lobes; } \\
\text { marked edema }\end{array}$ & - & + & + & $\mathrm{Y}$ & Improved \\
\hline 5 & 18 & M & Sorsogon & Sorsogon & $\mathrm{Y}$ & Y & $\begin{array}{c}\text { Multiple enhancing } \\
\text { nodules in frontal } \\
\text { and parietal lobes; } \\
\text { marked edema }\end{array}$ & + & + & + & $\mathrm{Y}$ & Improved \\
\hline 6 & 19 & M & Cebu & Paranaque & Y & Y & $\begin{array}{c}\text { No lesions, no } \\
\text { edema }\end{array}$ & + & + & - & $\mathrm{Y}$ & Improved \\
\hline 7 & 19 & M & Leyte & Leyte & Y & Y & $\begin{array}{l}\text { Solitary nodule in } \\
\text { frontal lobe; } \\
\text { marked edema }\end{array}$ & + & - & - & $\mathrm{Y}$ & Improved \\
\hline 8 & 22 & M & Leyte & $\begin{array}{c}\text { Mandaluyo } \\
\text { ng }\end{array}$ & Y & Y & $\begin{array}{l}\text { Multiple nodules in } \\
\text { frontal lobe }\end{array}$ & - & + & - & Y & $\begin{array}{l}\text { Lost to } \\
\text { follow up }\end{array}$ \\
\hline 9 & 24 & M & Marikina & Leyte & Y & $\mathrm{Y}$ & $\begin{array}{c}\text { Solitary nodule in } \\
\text { parietal lobe; no } \\
\text { edema }\end{array}$ & + & - & - & Y & Improved \\
\hline 10 & 26 & $\mathrm{~F}$ & $\begin{array}{l}\text { Or. } \\
\text { Mindoro }\end{array}$ & Manila & $?$ & Y & $\begin{array}{l}\text { Solitary non- } \\
\text { enhancing nodule } \\
\text { in parietal lobe; } \\
\text { marked edema } \\
\end{array}$ & - & + & - & $\mathrm{Y}$ & $\begin{array}{l}\text { Lost to } \\
\text { follow up }\end{array}$ \\
\hline 11 & 27 & M & $?$ & Caloocan & $?$ & Y & $\begin{array}{c}\text { Solitary nodule in } \\
\text { parietal lobe }\end{array}$ & - & + & - & $\mathrm{N}$ & $\begin{array}{l}\text { Lost to } \\
\text { follow up }\end{array}$ \\
\hline 12 & 29 & M & Paranaque & Paranaque & $?$ & $\mathrm{Y}$ & $\begin{array}{c}\text { Multiple enhancing } \\
\text { nodules in frontal, } \\
\text { parietal, occipital } \\
\text { lobes; marked } \\
\text { edema }\end{array}$ & - & + & - & $\mathrm{Y}$ & Improved \\
\hline 13 & 30 & M & Agusan & Pasay & $Y$ & $\mathrm{Y}$ & $\begin{array}{c}\text { Solitary enhancing } \\
\text { nodule in temporal } \\
\text { lobe }\end{array}$ & - & - & + & $Y$ & Improved \\
\hline 14 & 31 & $\mathrm{~F}$ & Cavite & Leyte & $\mathrm{Y}$ & Y & $\begin{array}{c}\text { Multiple enhancing } \\
\text { nodules in parietal } \\
\text { and occipital lobes; } \\
\text { mild edema }\end{array}$ & - & + & + & $Y$ & Unknown \\
\hline 15 & 31 & M & Cebu & Paranaque & $\mathrm{Y}$ & Y & $\begin{array}{c}\text { Multiple nodules in } \\
\text { frontal and parietal } \\
\text { lobes }\end{array}$ & - & - & - & $Y$ & Improved \\
\hline 16 & 32 & $\mathrm{M}$ & Leyte & Leyte & $Y$ & $\mathrm{Y}$ & $\begin{array}{c}\text { Multiple enhancing } \\
\text { nodules in parietal } \\
\text { and occipital lobes; } \\
\text { marked edema }\end{array}$ & - & + & - & $Y$ & Improved \\
\hline 17 & 34 & M & N.Samar & Caloocan & Y & $\mathrm{Y}$ & $\begin{array}{c}\text { Multiple nodules in } \\
\text { frontal and parietal } \\
\text { lobes }\end{array}$ & + & + & - & Y & Improved \\
\hline 18 & 35 & M & $\begin{array}{l}\text { Surigao } \\
\text { del Norte }\end{array}$ & Pasig & $?$ & Y & $\begin{array}{l}\text { Hypodensities in } \\
\text { frontal, parietal, } \\
\text { occipital lobes read } \\
\text { as 'chronic infarcts' }\end{array}$ & - & - & + & $Y$ & Improved \\
\hline
\end{tabular}




\begin{tabular}{|c|c|c|c|c|c|c|c|c|c|c|c|c|}
\hline 19 & 35 & $\mathrm{M}$ & N. Samar & Mandaluyong & $?$ & $\mathrm{Y}$ & $\begin{array}{c}\text { Multiple nodules in } \\
\text { parietal lobe; } \\
\text { marked edema }\end{array}$ & -- & - & + & $\mathrm{Y}$ & Improved \\
\hline 20 & 41 & M & $\begin{array}{c}\text { O. } \\
\text { Mindoro }\end{array}$ & $\begin{array}{l}\text { Oriental } \\
\text { Mindoro }\end{array}$ & $?$ & $\mathrm{Y}$ & $\begin{array}{l}\text { Multiple nodules in } \\
\text { parietal and } \\
\text { temporal lobes and } \\
\text { cerebellum; no } \\
\text { edema }\end{array}$ & - & + & - & $\mathrm{Y}$ & Improved \\
\hline 21 & 41 & M & Samar & Taguig & $\mathrm{Y}$ & $\mathrm{Y}$ & $\begin{array}{l}\text { Multiple nodules in } \\
\text { parietal lobe }\end{array}$ & - & - & + & $\mathrm{Y}$ & Improved \\
\hline 22 & 43 & M & Samar & Las Pinas & $\mathrm{Y}$ & $\mathrm{Y}$ & $\begin{array}{l}\text { Multiple enhancing } \\
\text { nodules in frontal, } \\
\text { parietal, temporal } \\
\text { lobes; mild edema }\end{array}$ & - & - & + & $\begin{array}{c}\mathrm{Y} \\
{[(+) \text { hepatic }} \\
\text { schistosomiasis }]\end{array}$ & Improved \\
\hline 23 & 44 & M & Leyte & Leyte & $\mathrm{Y}$ & $\mathrm{Y}$ & $\begin{array}{c}\text { Solitary enhancing } \\
\text { nodule in temporal } \\
\text { lobe; marked } \\
\text { edema }\end{array}$ & - & - & + & Y & Improved \\
\hline 24 & 47 & $\mathrm{~F}$ & Leyte & Leyte & $\mathrm{Y}$ & $\mathrm{Y}$ & $\begin{array}{l}\text { Large complex } \\
\text { minimally- } \\
\text { enhancing mass w/ } \\
\text { solid \& cystic } \\
\text { components in } \\
\text { frontal lobe }\end{array}$ & - & - & - & $\begin{array}{c}\mathrm{Y} \\
{[(+) \text { hepatic }} \\
\text { schistosomiasis }]\end{array}$ & Unknown \\
\hline 25 & 48 & $\mathrm{~F}$ & $\begin{array}{c}\text { Surigao } \\
\text { del Norte }\end{array}$ & Cavite & $?$ & Y & $\begin{array}{c}\text { Multiple nodules in } \\
\text { parietal lobe }\end{array}$ & - & - & + & Y & Improved \\
\hline 26 & 51 & $\mathrm{~F}$ & N. Samar & Makati & $\mathrm{Y}$ & $\mathrm{Y}$ & $\begin{array}{c}\text { Multiple nodules in } \\
\text { parietal and } \\
\text { occipital lobes }\end{array}$ & - & - & + & $\mathrm{Y}$ & Improved \\
\hline 27 & 55 & M & Leyte & Paranaque & $\mathrm{Y}$ & $\mathrm{Y}$ & $\begin{array}{c}\text { Multiple nodules in } \\
\text { parietal and } \\
\text { occipital lobes }\end{array}$ & + & + & - & Y & Unknown \\
\hline 28 & 60 & $\mathrm{~F}$ & E.Samar & $\begin{array}{l}\text { Quezon } \\
\text { City }\end{array}$ & $\mathrm{Y}$ & $\mathrm{Y}$ & $\begin{array}{c}\text { Multiple nodules in } \\
\text { parietal and } \\
\text { occipital lobes }\end{array}$ & - & - & + & $\mathrm{Y}$ & Improved \\
\hline 29 & 68 & M & $\begin{array}{l}\text { Lanao } \\
\text { del Sur }\end{array}$ & Taguig & $\mathrm{Y}$ & $\mathrm{Y}$ & $\begin{array}{l}\text { Solitary nodule in } \\
\text { parietal lobe }\end{array}$ & - & - & + & $\begin{array}{c}\mathrm{Y} \\
{[(+) \text { hepatic }} \\
\text { schistosomiasis }]\end{array}$ & Improved \\
\hline
\end{tabular}

?= not stated

Mild edema: size of edema < size of nodule

Moderate edema: size of edema approximates that of nodule

Marked edema: size of edema > size of nodule 